UDC 327

Submitted: 30.09.2018

LBC 66.4(2Poc)

Accepted: 27.12 .2018

\title{
INTERNATIONAL LEGITIMIZATION \\ OF RUSSIAN FOREIGN POLICY ACTIONS IN THE CONTEXT \\ OF THE UKRAINIAN AND SYRIAN CONFLICTS: THE 'RESPONSIBILITY TO PROTECT' CONCEPTION
}

\author{
Asiyat A. Tarchokova \\ Russian Presidential Academy of National Economy and Public Administration, Moscow, Russian Federation
}

\begin{abstract}
Introduction. The complexity of foreign policy actions' international legitimization is determined by the use of unilateral approach in the new environment of world political processes. Due to Russian foreign policy's intensification, the issue of international legitimization of its foreign policy actions has expanded and deepened in the post-Soviet space and beyond: it is obvious in practice, but not conceptualized at the theoretical level. Methods. It seems to be of utmost importance to consider the problem in the context of the recent most pressing events - the Ukrainian and Syrian conflicts, using the case-study method as well as through the perceptualhermeneutic analysis of foreign policy actions. Analysis. The need to do research in legitimization as a process of justification and achievement of a foreign policy position's recognition is obvious. It is necessary to highlight the reasons for the ineffectiveness of Russian foreign policy actions' justification instruments and legitimization policy. Results. The assessment and conceptualization of existing legal and political concepts is particularly important to build an international legitimization foreign policy strategy. The implementation of foreign policy action should be accompanied by the transfer of basic foreign policy values and interests, combining legal, political, and moral grounds. The improvement of the international legitimization mechanism, its tools' rapid revitalization and operating flexibility can give Russia an indisputable advantage over other actors and allow it to ensure the necessary result for the foreign policy strategy and strengthen its positioning in the international environment.

Key words: legitimization, Russian foreign policy, Crimea, Syria, chemical weapon, unilateral actions, legitimacy, Responsibility to Protect.
\end{abstract}

Citation. Tarchokova A.A. International Legitimization of Russian Foreign Policy Actions in the Context of the Ukrainian and Syrian Conflicts: the 'Responsibility to Protect' Conception. Vestnik Volgogradskogo gosudarstvennogo universiteta. Seriya 4, Istoriya. Regionovedenie. Mezhdunarodnye otnosheniya [Science Journal of Volgograd State University. History. Area Studies. International Relations], 2019, vol. 24, no. 1, pp. 207-215. (in Russian). DOI: https://doi.org/10.15688/jvolsu4.2019.1.18

УДК 327

ББК 66.4(2Poc)
Дата поступления статьи: 30.09.2018

Дата принятия статьи: 27.12.2018

\footnotetext{
МЕЖДУНАРОДНАЯ ЛЕГИТИМИЗАЦИЯ ДЕЙСТВИЙ ВО ВНЕШНЕЙ ПОЛИТИКЕ РОССИИ В КОНТЕКСТЕ УКРАИНСКОГО И СИРИЙСКОГО КОНФЛИКТОВ: КОНЦЕПЦИЯ «ОТВЕТСТВЕННОСТЬ ПО ЗАЩИТЕ»

\section{Асият Арсеновна Тарчокова}

Российская академия народного хозяйства и государственной службы при Президенте РФ, г. Москва, Российская Федерация

Аннотация. Введение. Сложность международной легитимизации внешнеполитических действий определяется применением унилатерального подхода в новых условиях развития мирополитических процессов.
} 
В связи с активизацией внешней политики России на постсоветском пространстве и за ее пределами проблема международной легитимизации ее внешнеполитических действий расширилась и углубилась: она очевидна в практической деятельности, но не концептуализирована на теоретическом уровне. Методы. Представляется наиболее важным рассмотреть данную проблему в контексте последних наиболее острых внешнеполитических событий - украинского и сирийского конфликтов - с применением метода case-study, а также через перцептивно-герменевтический анализ внешнеполитических действий. Анализ. Очевидна необходимость исследования легитимизации как процесса оправдания и достижения признания внешнеполитической позиции. Необходимо выделить причины неэффективности инструментов оправдания и обоснования внешнеполитических действий и легитимизационной политики России. Результаты. Особенно важны оценка и концептуализация существующих правовых и политических концепций с целью построения внешнеполитической стратегии международной легитимизации. Реализацию внешнеполитического действия необходимо обеспечить сопровождением трансляции основных внешнеполитических ценностей и интересов, сочетая правовые, политические и морально-нравственные основания. Совершенствование механизма международной легитимизации, быстрая активизация и гибкость оперирования его инструментарием наделят Россию неоспоримым преимуществом перед другими акторами, позволят обеспечить внешнеполитическую стратегию необходимым результатом и усилить ее позиционирование в международной ситуации.

Ключевые слова: легитимизация, внешняя политика России, Крым, Сирия, химическое оружие, односторонние действия, легитимность, «ответственность по защите».

Цитирование. Тарчокова А. А. Международная легитимизация действий во внешней политике России в контексте украинского и сирийского конфликтов: концепция «ответственность по защите» // Вестник Волгоградского государственного университета. Серия 4, История. Регионоведение. Международные отношения. - 2019. - Т. 24, № 1. - С. 207-215. - DOI: https://doi.org/10.15688/jvolsu4.2019.1.18

Введение. Феномен глобализации и сопровождающие ее процессы обусловили формирование особенностей начала новой эпохи, определяемой во многом состоянием, когда проблема «устойчивости мировой политической системы представлена антиномией “национальное государство" - “всемирность" (“мировое общество”)» [8, с. 252]. Именно поэтому сегодня уже недостаточно ресурса внутригосударственной легитимности, новая мирополитическая реальность требует достижения всемирной, глобальной легитимности со стороны международного сообщества. «Всемирность в политическом смысле характеризуется тем, что устойчивость обеспечивается одновременным усилением и ограничением власти включенных в нее государств» [8, c. 252]. Когда процессы усиления власти ускоряют свое развитие, а процессы ее ограничения запаздывают, ввиду ослабления механизмов сдерживания гегемониальных устремлений, система сдержек и противовесов обретает состояние дисбаланса, близкое к одностороннему доминированию - примату односторонних национальных интересов над интересами международного сообщества в целом (глобальными интересами) и отдельных ее участников, которое вступает в противоречие с самой природой государственности, чем и обусловлено встречное сопротивление доминанту других акторов.

Современный период развития международных отношений, детерминируемый ростом новых центров влияния и изменением баланса сил, можно назвать кризисом одностороннего доминирования, который требует оформления новых правил внешнеполитического поведения и повышения уровня легитимности применяемых во внешней политике подходов. В таких условиях недостаток доверия и поддержки со стороны международного сообщества снижает легитимность унилатерального подхода ${ }^{1}$. Подобное состояние международной системы определяет важность рассмотрения международной легитимизации внешнеполитических действий ${ }^{2}$ в контексте условий формирования новых центров силы.

Если ранее изучение проблемы односторонних действий во внешней политике было сосредоточено преимущественно на политике Соединенных Штатов, то в последнее десятилетие международное экспертное сообщество усматривает элементы односторонности во внешнеполитической стратегии и других стран: Китая, Израиля и в том числе России, что стало предметом широкой дискуссии между российскими и зарубежными экспертами, начиная с грузинского конфликта 
2008 года. Актуализировались такие дебаты и в контексте украинского и сирийского кризисов, поставивших вопросы легитимизации вхождения Крыма в состав России и российской военной операции в Сирии.

В условиях трансформирующейся международной системы внешняя политика России, активизировавшаяся в последние годы не только на постсоветском пространстве, но и за его пределами, сталкивается с проблемой обеспечения легитимности действий перед международным сообществом, что значительно осложняет задачу поддержания и укрепления ее авторитета и имиджа на мировой арене, повышает негативные эффекты реализации внешнеполитических интересов. Проблемы международной легитимизации российских внешнеполитических действий еще более расширились и углубились: они очевидны в практической деятельности, но не концептуализированы на теоретическом уровне. Особенно значимым на данный момент представляется вопрос обеспечения легитимизации внешнеполитических действий России в рамках последних наиболее острых конфликтов на Украине и в Сирии.

Методы и материалы. В данной статье обозначенные вопросы исследованы с примененением метода case-study и элементов перцептивно-герменевтического анализа внешнеполитических действий, а также в качестве эмпирики использованы доклады зарубежных экспертов, резолюции, отчеты и иные материалы заседаний Совета Безопасности и Генеральной Ассамблеи ООН по исследуемым кейсам.

Анализ. Политика России в отношении Украины с февраля 2014 г. интерпретировалась Западом как политическое и вооруженное вмешательство в конфликт. Если рассматривать внешнеполитические действия России по отношению к Украине в качестве объекта легитимизации, то следует выделить ряд оснований, отмечаемых в российской официальной позиции.

Первое основание - «прямое обращение действующего и легитимного президента Украины Януковича об использовании Вооруженных сил для защиты жизни, свободы и здоровья граждан Украины» [2]. Второе основание - обращение властей Республики Крым к президенту России с просьбой «оказать содействие в восстановлении спокойствия в Крыму» [5].

После обращения президента Советом Федерации был рассмотрен вопрос о возможности использования Вооруженных сил за пределами территории Российской Федерации. И хотя президент России ею не воспользовался, риторика возможности их ввода трансформировалась на Западе в их фактическое применение, что породило множество обсуждений о правомерности и основаниях такого шага.

Фактическое вооруженное вмешательство не состоялось, однако без наличия самого предмета оправдания Запад начал искать обоснования и методы легитимизации, которые якобы были применены российской стороной. При этом важно отметить, что «растущий ком дискуссий возник преимущественно вокруг обоснования предполагаемого военного вмешательства, но не обоснования присоединения Крыма, поскольку здесь Запад сталкивается с соотношением международно-правовых принципов территориальной целостности и самоопределения народов, о противоречии между которыми по настоящее время ведутся споры между юристами-международниками, а также в связи с прецедентом Косово, на который ссылается Россия в ответ на осуждения о неправомерности проведения референдума» [7, с. 35].

Нахождение подразделений российских вооруженных сил на полуострове Крым согласно договору с Украиной было расценено западным обществом как вооруженная интервенция и агрессия, нарушение территориальной целостности Украины. При этом такая позиция поддерживается большинством участников международного сообщества, если учитывать голосование Генеральной Ассамблеи ООН по статусу и милитаризации Крыма ${ }^{3}$. Акт России по оказанию помощи и поддержки действующей и легитимной de jure власти не был убедителен в своей легитимности для международного сообщества как в политическом, так и в юридическом поле. Ввиду этого целесообразно рассматривать украинский кейс в качестве платформы недостаточно эффективной легитимизации внешнеполитических действий России. 
Российское экспертное сообщество избегает создания каких-либо формулировок в обоснование действий России относительно Украины, легитимизирующих ее внешнеполитическую позицию и политику в этом направлении в целом. Однако западные эксперты по сегодняшний день ведут споры и дискуссии по обоснованию вмешательства, которого, согласно официальной позиции России, не было. Так, самой популярной версией обоснования действий России относительно Украины в 2014 г. и Грузии в 2008 г. стала концепция западного происхождения Responsibility to Protect (или R2P) - «ответственность по защите» ${ }^{4}$.

Позиция России по доктрине «ответственность по защите» отражена в Концепции внешней политики: Российская Федерация намерена «не допускать осуществления под предлогом реализации концепции “ответственность по защите” военных интервенций и прочих форм стороннего вмешательства, нарушающих нормы международного права, в частности принцип суверенного равенства государств» [3].

В 2014 г. в Королевском институте международных отношений Chatham House был опубликован доклад по применению международного права к украинскому конфликту. В нем были озвучены и объяснены возможные правовые и политические подходы к оправданию, по которым, согласно их мнению, действовала Россия, присоединяя Крым к своей территории. Эксперты Королевского института, сравнивая прецеденты в Косово и Украине, пришли к следующему выводу: даже если предположить, что вмешательство в Косово является нарушением международного права, аргумент о том, что Россия может совершить такое же нарушение, является не юридическим аргументом, а политическим. А в связи с появлением понятия «ответственность по защите» (R2P) Россия, как и некоторые другие государства, неохотно согласилась на решительные обязательства по R2P, поскольку это ограничило бы ее полномочия в принятии решений, в том числе в Совете Безопасности ООН [15].

Применительно к российской политике итальянский политолог Джиованна де Майо концепцию R2P связывает с ранее открытой идеей «Русского мира» как единого культурного пространства. По утверждению политолога, конкретная ссылка на концепцию была сделана в 2008 г. министром иностранных дел России Сергеем Лавровым, который «для оправдания вмешательства России в конфликт охарактеризовал события в Республике Южная Осетия как геноцид» [9].

Предположительной моделью международного вмешательства в суверенные страны в целях защиты гражданских лиц, как утверждает эксперт Мэг Сулливан, стало участие Соединенных Штатов и других западных стран в операции в Ливии в 2011 г. [14]. Совет Безопасности $\mathrm{OOH}$ обратился к R2P с тем, чтобы остановить кровопролитие и оправдать вмешательство НАТО в Ливии. После прекращения режима Муаммара Каддафи, как принято считать, международное сообщество продемонстрировало, что R2P является более чем простой риторикой. В результате принятия желаемого за действительное Запад столкнулся с трудностями повторения вмешательства в стиле R2P в Сирии [10].

Согласно мнению эксперта Марка Керстена, R2P также является своего рода речевым стилем и в качестве такового выступает «двухклинковым мечом», восприимчивым к применению и злоупотреблению; понимание R2P зависит от того, кто его интерпретирует. R2P был предназначен для обеспечения платформы для оправдания гуманитарных действий и бездействий. Но это также позволяет государствам злоупотреблять концепцией, применяя ее выборочно, когда они посчитают ее подходящей ситуации [11].

Эксперт М. Сулливан, ссылаясь на слова министра иностранных дел России, утверждает, что «Россия развернула риторику в стиле R2P, чтобы оправдать военное вмешательство. При вторжении в Грузию в 2008 г. высокопоставленные российские официальные лица утверждали, что их действия оправданы на основании ответственности России по защите российских граждан в Южной Осетии и Абхазии» [14] и что на Украине Россия находилась в очень близкой с этой ситуацией позиции. Согласно мнению западного эксперта, президент России публично обратился к R2P в качестве, по крайней мере, частичного оправдания его вмешательства в Крым. 
Что касается сирийского конфликта, по состоянию на 30 января 2018 г. концепция R2P упоминалась в пяти резолюциях Совета Безопасности ООН (далее - СБ ООН), которые содержали призывы и требования ко всем сторонам конфликта «предпринять все необходимые меры для защиты гражданского населения Сирии независимо от этнической, религиозной и конфессиональной принадлежности» и возлагали ответственность по защите населения на сирийское правительство ${ }^{5}$. Однако, как указала в своем исследовании Дженна Руссо, несмотря на возрастающую частоту цитирования концепции, сирийский кейс выявил глубину политических и идеологических разногласий между государствами - членами СБ ООН, связанных с внедрением третьего компонента R2P, ставя под сомнение его эффективность. В случае с Сирией Запад использовал каждую возможность, чтобы возложить весь груз ответственности на Россию, представив ее в качестве основного нарушителя [13].

В качестве оснований внешнеполитических действий России в Сирии приводится официальное обращение за оказанием военной поддержки от легитимного руководителя Сирийской Арабской Республики, а также Соглашение между Россией и Сирией о размещении авиационной группы Вооруженных сил России на бессрочный период и на безвозмездной основе (в провинции Латакия, аэродром «Хмеймим») от 26 августа 2015 г. [6].

В Концепции внешней политики России закреплено соответствующее положение о подходе России к участию во внешнеполитических операциях с приоритетным вниманием международному сотрудничеству в противодействии терроризму, в том числе путем применения военной силы, с согласия государств, на территориях которых ведется борьба с террористическими организациями и группировками [3].

Россия избегает прямого указания на концепцию R2P в качестве обоснования своих действий в Сирии. Легитимизация российской операции, при, казалось бы, достаточных правовых и политических основаниях значительно усложнена ввиду разнонаправленности целей присутствия ряда акторов в регионе, в частности коалиции США. Это объясняет причины появления различных противоречий и интерпретаций действий сторон с целью обосновать и оправдать свои собственные, противопоставляя положительный характер своих действий негативному характеру действий других сторон. Сирийский кейс особенно обременен высокой политизированностью освещения конфликта заинтересованными лицами и созданием параллельных двух картин происходящего и собственного видения роли акторов в них.

Цель миротворческих операций и разрешения конфликтов для США и большинства европейских государств «заключается в защите индивидуальных прав и свобод и достижении “демократического транзита" путем создания либерально-демократического режима на месте авторитарного» [1, с. 159]. При этом «позиция Запада по поддержанию мира в последние десятилетия определялась либеральной идеологией с элементами интервенционизма» [1, с. 159]. Именно на этой идеологии и строились западные концепции защиты прав человека, гуманитарной интервенции, концепция «ответственность по защите». Для России же первоочередная цель миротворчества, в частности, в Сирии - восстановление и сохранение государства, которое будет способно бороться с терроризмом, установление демократического правления.

В российской официальной позиции отмечается, что и астанинский формат, и Конгресс национального диалога не дублируют женевский процесс урегулирования сирийского конфликта. Наряду с легитимизацией политического процесса через женевский формат, проведение Конгресса в России - это одобренный $\mathrm{OOH}$ механизм, который также способствует легитимизации внешнеполитической позиции России по Сирии. Заявляя о своей приверженности резолюции СБ ООН 2254, Россия объявляет два ее ключевых положения о Конституции Сирии и всеобщих выборах главными задачами примирительного Конгресса национального диалога. Таким образом, астининский и сирийский форматы переговоров являются вспомогательными к женевскому формату, без которых, по признанию самой Сирии [4], не возможен прогресс женевского переговорного процесса.

Важно отметить, что интересное сходство с критериями R2P прослеживается в 


\section{ПОЛИТИЧЕСКИЕ НАУКИ И РЕГИОНОВЕДЕНИЕ}

сирийском сюжете о применении химического оружия. Западная аргументация по обвинению сирийского правительства в применении химического оружия по отношению к своим гражданам и необходимости принятия ряда мер концептуально совпадает с предыдущими сценариями применения R2P в международной практике. Это свидетельствует о том, что нельзя в перспективе исключать возможность применения предыдущих удачных сюжетов легитимизации - политического инструментального ресурса легитимизации - в качестве идейного источника для создания идентичных историй под готовые, имевшие прецеденты концепции, которые уже получили признание в мировом общественном мнении.

В случае с химическим оружием Запад пошел дальше предписаний любых гуманитарных концепций и до начала расследования Организации по запрещению химического оружия (далее - О3ХО) применил наказание к полагаемому нарушителю. Такая риторика США, возглавляющих коалицию ${ }^{6},-$ явный признак намерения не защитить гражданское население, а наказать правительственные силы Сирии, что свидетельствует о нарушении не только международно-правовых норм, но и принципов политических концепций, в том числе «ответственности по защите». Стоит отметить, что как в апреле 2017 г. в Хан-Шейхуне (Идлиб), так и в апреле 2018 г. в Думе (Восточная Гута) заявления о применении химического оружия сопровождались ракетными ударами западной коалиции (в 2017 г. по сирийской авиабазе Шайрат, в 2018 г. - по ряду объектов, в том числе авиационных баз сирийских ВВС) с отрывом лишь в несколько дней - временной период, относительно достаточный для восприятия информации международным сообществом и формирования мирового общественного мнения, но недостаточный для установления фактов и расследования инцидентов через механизм О3ХО, как и должного анализа произошедшего и последующего реагирования.

Ракетные удары по правительственным военным объектам в Сирии интерпретируются как наказание за нарушение - справедливая ответная мера, реализованная западной коалицией от имени и во спасение международного со- общества от угрозы со стороны агрессора. Важно отметить, что при этом коалиция действовала без мандата как международного сообщества в лице СБ ООН, так и институциональных структур безопасности и военно-политических блоков. Известно также, что большинство стран НАТО не принимали участия в операции и даже выступали против нее до выяснения всех обстоятельств инцидента в Думе.

Следовательно, ударом по Сирии США и их союзники хотели оправдать свое присутствие в регионе, а привлечением сюжета с применением химического оружия - легитимизировать свои внешнеполитические действия по отношению к Сирии.

Более того, анализ внутреннего документа $\mathrm{OOH}$ «Параметры и принципы содействия $\mathrm{OOH}$ в Сирии», обнародованного только спустя почти год после издания, позволяет констатировать, что ООН без вынесения на рассмотрение и обсуждение данного вопроса в соответствующих органах (Совете Безопасности, Генеральной Ассамблее или Совете по правам человека $\mathrm{OOH})$ на внутреннем уровне решил гуманитарный вопрос, самостоятельно установив условия оказания помощи в Сирии. Одно из положений приведенного документа закрепляет, что «только после того, как будет осуществлен подлинный и всеобъемлющий согласованный сторонами политический переход власти, ООН будет готова содействовать реконструкции и восстановлению в Сирии» [12]. Существование данной негласной директивы опять же свидетельствует не в пользу версии о первичности гуманитарных целей Запада в Сирии.

Результаты. По итогам исследования, можно сделать вывод, что цели и идеи, представляемые в российской официальной позиции не всегда достигают легитимизационных задач, а именно обеспечения признания международным сообществом легитимными внешнеполитических действий России в отношении Украины и Сирии ${ }^{7}$. Причины их недостаточной эффективности в роли инструмента оправдания и обоснования внешнеполитических действий могут заключаться в том, что эти цели и идеи недостаточно оформлены в виде теорий и концепций (правовых, политико-правовых, моральных и т. п.). Следовательно, они не в полной мере доступны международному сообществу. 
Необходимо выносить их на широкое обсуждение и продвигать на различных площадках: общественных, экспертно-научных, политических, в особенности на площадках $\mathrm{OOH}$, в том числе в работе ее комитетов и в СБ ООН. И наконец, в недостаточной степени учтены особенности восприятия и интерпретации действий международным сообществом, а также факторы, влияющие на эти особенности как в процессе событий, так и post festum.

Действия России в Грузии, на Украине и в Сирии трактуются и интерпретируются как односторонние, прежде всего в связи с видением ее внешнеполитического курса и стратегии через призму ревизионизма и в духе империализма. Такая интерпретация благоприятно ложится в контекст западных концепций, фундируя и противопоставляя заложенные в них ценности российской политике, рассматриваемой Западом в качестве ревизионистской.

Таким образом, России на сегодняшний день необходимо делегитимизационному воздействию противопоставить свои основные внешнеполитические ценности, достигнув их концептуализации и оформления, поскольку только в оформленном виде они доступны международному сообществу и способны эффективно влиять на мировое общественное мнение.

На конкурентном поле продвижения национальных интересов современная внешняя политика России в отношении целей и методов миротворческой деятельности должна рассматриваться в рамках стратегического мировоззрения России и понимания ею нового международного порядка.

При принятии внешнеполитического решения и последующей реализации внешнеполитического действия важно обеспечить отражение основных внешнеполитических ценностей и интересов через сбалансированное сочетание правовых подходов, моральных оснований и политической целесообразности, применяя более гибкие комбинации и формулировки в противодействие квазидоказательствам и аргументам. Эта система несет в себе определенные риски, но и открывает новые возможности в легитимизационном поле. Основная цель при этом - минимизация правовых и репутационных рисков в формирова- нии международного общественного мнения относительно внешней политики России.

Потенциальные ресурсы инструментов легитимизации неисчерпаемы, но возможность овладеть и умело воспользоваться ими зависит от многих факторов, и прежде всего от рационально ориентированного и стратегически продуманного и разработанного механизма легитимизации внешнеполитических действий.

И в особенности, учитывая одностороннюю риторику действующей администрации США по отношению к международному праву и международно-правовым обязательствам (Парижское соглашение по климату, выход из соглашения по Совместному всеобъемлющему плану действий по ядерной программе Ирана (СВПД), выход из ЮНЕСКО, Совета по правам человека $\mathrm{OOH}$, из-под юрисдикции Международного суда $\mathrm{OOH}$ ), Россия могла бы сегодня в рамках внешнеполитической стратегии использовать такой протест геополитического оппонента в качестве ресурса для повышения своего авторитета как передового инициатора движения международно-правового комплаенса и хранителя международного порядка.

\section{ПРИМЕЧАНИЯ}

1 Посредством анализа ряда англоязычных толковых словарей (Oxford Pocket Dictionary of Current English, American Heritage, Merriam Webster и др.) унилатерализм можно определить как политику ведения односторонних действий в международных отношениях вне зависимости от поддержки и взаимодействия с другими государствами.

${ }^{2}$ Международную легитимизаичю внешнеполитических действий автор определяет как «обеспечение признания и подтверждения международным сообществом права на реализацию внешнеполитического решения и/или действия актора, объяснение и достижение восприятия его международным сообществом как оправданного, должного, оптимального и адекватного ситуации» [7, c. 34].

${ }^{3}$ Резолюции, принятые Генеральной Ассамблеей ООН: A/RES/68/262 «О территориальной целостности Украины» (от 27 марта 2014 г. ) иА/73/L.47 «Проблема милитаризации Автономной Республики Крым и города Севастополь, Украина, а также районов Черного и Азовского морей» (от 17 декабря 2018 г.). 
4 «Концепция Responsibility to Protect (R2P, или RtoP) - “ответственность по защите”, или “обязательство по защите”, - предусматривает ряд взаимосвязанных обязательств государств по защите населения от четырех видов наиболее опасных международных преступлений: геноцида, военных преступлений, этнических чисток и преступлений против человечности. При этом первоначально обязанность защищать своих граждан лежит на государственных властях, однако в случае ее невыполнения ответственность по защите ложится на все мировое сообщество, действующее посредством ООН, даже если это потребует нарушения государственного суверенитета» [7, с. 35].

5 Резолюции Совета Безопасности ООН: S/RES/2139 (2014), 22 February 2014; S/RES/2165 (2014), 14 July 2014; S/RES/2254 (2015), 18 December 2015; S/RES/2258 (2015), 22 December 2015; S/RES/ 2332 (2016), 21 December 2016.

6 Другие члены коалиции - Великобритания и Франция - заявили, что военная операция направлена против химического арсенала сирийского режима и на избежание эскалации напряженности и жертв среди гражданского населения.

${ }^{7}$ Об этом можно судить по резолюциям Генеральной Ассамблеи ООН по статусу Крыма и Севастополя и ситуации с правами человека на их территориях, о положении в Сирии, а также международному давлению и широкому осуждению внешнеполитических действий России.

\section{СПИСОК ЛИТЕРАТУРЫ}

1. Братерский, М. В. Россия и миротворческие операции: концептуальные и практические составляющие российской политики / М. В. Братерский // Вестник международных организаций. 2018. - T. 13, № 1.-C. 157-170. -DOI: 10.17323/19967845-2018-01-09.

2. Владимир Путин ответил на вопросы журналистов о ситуации на Украине. - Электрон. текстовые дан. - Режим доступа: http://kremlin.ru/ events/president/news/20366 (дата обращения: 21.07.2018). - Загл. с экрана.

3. Концепция внешней политики Российской Федерации : утв. Указом Президента Рос. Федерации № 640 от 30 нояб. 2016 г. // Собрание законодательства РФ. - 2016. - № 49. - Ст. 6886.

4. Муаллем, В. США хотят, чтобы Сирия стала одним из их инструментов в мировой политике / В. Муаллем // Международная жизнь. - 2018. № 9. - C. 6-10.

5. Отчет по 7125-му заседанию Совета Безопасности ООН. Нью-Йорк, 3 марта 2014 года. - Элек- трон. текстовые дан. - Режим доступа: https:// documents-dds-ny.un.org/doc/UNDOC/PRO/N14/ 250/48/PDF/N1425048.pdf (дата обращения: 21.07.2018). - Загл. с экрана.

6. Соглашение между Российской Федерацией и Сирийской Арабской Республикой о размещении авиационной группы Вооруженных Сил Российской Федерации на территории Сирийской Арабской Республики // Собрание законодательства РФ. - 2017. - № 4. - Ст. 522.

7. Тарчокова, А. А. Инструменты международной легитимации внешнеполитических действий России в условиях информационного противоборства / А. А. Тарчокова, Д. А. Медведев // Информационные войны. - 2018. - № 3 (47). C. 34-37.

8. Шевченко, А. В. Конфликтологический подход к обеспечению устойчивости мировой политической системы / А. В. Шевченко // Конфликтология. - 2014. - № 2. - С. 251-253.

9. De Maio, G. Russia's View of Ukraine after the Crisis / G. De Maio // IAI : Working Papers 16. 2016. - Febr. 4. - Electronic text data. - Mode of access: http://www.iai.it/sites/default/files/iaiwp1604.pdf. Title from screen.

10. Kersten, M. Does Russia Have a 'Responsibility To Protect' Ukraine? Don't buy it. The Globe and Mail / M. Kersten. - Electronic text data. - Mode of access: https://www.theglobeandmail.com/globe-debate/doesrussia-have-a-responsibility-to-protect-ukraine-dontbuy-it/article17271450/.- Title from screen.

11. Kersten, M. Russia's Responsibility to Protect the Ukraine / M. Kersten. - Electronic text data. Mode of access: https://justiceinconflict.org/2014/03/ 05/russias-responsibility-to-protect-in-ukraine/. - Title from screen.

12. Parameters and Principles of UN assistance in Syria (October 2017). - Electronic text data. Mode of access: https:/www.kommersant.ru/docs/ 2018/UN-Assistane-in-Syria-2017.pdf. - Title from screen.

13. Russo, J. The Politics of R2P and Inaction in Syria: U.S., Russian, and Chinese Responses / J. Russo. Electronic text data. - Mode of access: https://www. imemo.ru/files/File/ru/conf/2018/23012018/Russo.pdf. Title from screen.

14. Sullivan, M. Justifying Crimea: President Putin Invokes R2P. April 11, 2014 / M. Sullivan. Electronic text data. - Mode of access: http://www. brownpoliticalreview.org/2014/04/justifying-crimeapresident-putin-invokes-r2p/. - Title from screen.

15. The Ukrainian Crisis: An International Law Perspective. - Electronic text data. - Mode of access: https://www.chathamhouse.org/sites/files/chathamhouse/ field/field_document/20140711UkraineLaw_0.pdf. - Title from screen. 


\section{REFERENCES}

1. Braterskiy M.V. Rossiya i mirotvorcheskie operatsii: kontseptualnye i prakticheskie sostavlyayushchie rossiyskoy politiki [Russia and Peacekeeping Operations: Conceptual and Practical Components of the Russian Policy]. Vestnik mezhdunarodnykh organizatsiy [International Organizations' Research Journal], 2018, vol. 13, no. 1, pp. 157-170. DOI: 10.17323/1996-7845-2018-01-09.

2. Vladimir Putin otvetil na voprosy zhurnalistov o situatsii na Ukraine [Putin's Interview about the Situation in Ukraine]. URL: http://kremlin.ru/ events/president/news/20366 (accessed 21 July 2018).

3. Kontseptsiya vneshney politiki Rossiyskoy Federatsii: utv. Ukazom Prezidenta Ros. Federatsii № 640 ot 30 noyab. 2016 g. [The Conception of the Foreign Policy of the Russian Federation: Approved by Presidential Decree No. 640 of November 30, 2016]. Sobranie zakonodatelstva $R F$ [Collected Legislation of the Russian Federation], 2016, no. 49, art. 6886.

4. Muallem V. SShA khotyat, chtoby Siriya stala odnim iz ikh instrumentov v mirovoy politike [The USA Want Syria to Become One of Their Tools in World Politics]. Mezhdunarodnaya zhizn [International Trends], 2018, no. 9, pp. 6-10.

5. Otchet po 7125-mu zasedaniyu Soveta Bezopasnosti OON. Nyu-York, 3 marta 2014 goda [Report on the 7125th Meeting of the UN Security Council. New York, March 3, 2014]. URL: https:// documents-dds-ny.un.org/doc/UNDOC/PRO/N14/ 250/48/PDF/N1425048.pdf

6. Soglashenie mezhdu Rossiyskoy Federatsiey i Siriyskoy Arabskoy Respublikoy o razmeshchenii aviatsionnoy gruppy Vooruzhennykh Sil Rossiyskoy Federatsii na territorii Siriyskoy Arabskoy Respubliki [Agreement between the Russian Federation and the Syrian Arab Republic on the Deployment of Aviation Group of the Russian Federation Armed Forces on the Territory of the Syrian Arab Republic]. Sobranie zakonodatelstva $R F$ [Collected Legislation of the Russian Federation], 2017, no. 4, art. 522.

7. Tarchokova A.A., Medvedev D.A. Instrumenty mezhdunarodnoy legitimatsii vneshnepoliticheskikh deystviy Rossii $\mathrm{v}$ usloviyakh informatsionnogo protivoborstva [Instruments of International Legitimization of Russian Foreign Policy Actions in the Context of Informational Confrontation]. Informatsionnye voyny [Information Wars], 2018, no. 3 (47), pp. 34-37.

8. ShevchenkoA.V. Konfliktologicheskiy podkhod $\mathrm{k}$ obespecheniyu ustoychivosti mirovoy politicheskoy sistemy [Conflictological Approach to Ensuring the Sustainability of the World Political System]. Konfliktologiya [Conflictology], 2014, no. 2, pp. 251-253.

9. De Maio G. Russia's View of Ukraine after the Crisis. IAI: Working Papers 16, 2016, Febr. 4. URL: http://www.iai.it/sites/default/files/iaiwp1604.pdf.

10. Kersten M. Does Russia Have a 'Responsibility To Protect' Ukraine? Don't buy it. The Globe and Mail. URL: https://www.theglobeandmail.com/globe-debate/ does-russia-have-a-responsibility-to-protect-ukrainedont-buy-it/article17271450/.

11. Kersten M. Russia's Responsibility to Protect the Ukraine. URL: https://justiceinconflict.org/2014/03/ 05/russias-responsibility-to-protect-in-ukraine/.

12. Parameters and Principles of UN assistance in Syria (October 2017). URL: https://www.kommersant.ru/ docs/2018/UN-Assistane-in-Syria-2017.pdf.

13. Russo J. The Politics of R2P and Inaction in Syria: U.S., Russian, and Chinese Responses. URL: https://www.imemo.ru/files/File/ru/conf/2018/ 23012018/Russo.pdf.

14. Sullivan M. Justifying Crimea: President Putin Invokes R2P. April 11, 2014. URL: http://www. brownpoliticalreview.org/2014/04/justifying-crimeapresident-putin-invokes-r2p/.

15. The Ukrainian Crisis: An International Law Perspective. URL: https://www.chathamhouse.org/ sites/files/chathamhouse/field/field_document/ 20140711UkraineLaw_0.pdf.

\section{Information about the Author}

Asiyat A. Tarchokova, Senior Lecturer, Department of International Security and Russian Foreign Policy, Russian Presidential Academy of National Economy and Public Administration, Prosp. Vernadskogo, 84, 119571 Moscow, RussianFederation, asia.17@mail.ru, https://orcid.org/0000-0002-7570-1878

\section{Информация об авторе}

Асият Арсеновна Тарчокова, старший преподаватель кафедры международной безопасности и внешнеполитической деятельности России, Российская академия народного хозяйства и государственной службы при Президенте РФ, просп. Вернадского, 84, 119571 г. Москва, Российская Федерация, asia.17@mail.ru, https://orcid.org/0000-0002-7570-1878 